\title{
Recurrent Childhood Protoplasmic Astrocytoma
}

National Cancer Institute

\section{Source}

National Cancer Institute. Recurrent Childhood Protoplasmic Astrocytoma. NCI

Thesaurus. Code C115376.

The reemergence of protoplasmic astrocytoma in childhood after a period of remission. 